\title{
Effect of high temperature exposure on epoxy-coated glass textile reinforced mortar (GTRM) composites
}

\author{
Massimo Messori ${ }^{\mathrm{a}}$, Andrea Nobili $^{\mathrm{a}}$, Cesare Signorini $^{\mathrm{b}, \mathrm{c}, *}$, Antonella Sola $^{\mathrm{a}}$ \\ ${ }^{a}$ Dipartimento di Ingegneria Enzo Ferrari, via Vivarelli 10, 41125 Modena, Italy \\ ${ }^{b}$ Dipartimento di Scienze e Metodi dell'Ingegneria, via Amendola 2, 42122 Reggio Emilia, \\ Italy \\ ${ }^{c}$ Dipartimento di Economia, Scienze e Diritto, Via Consiglio dei Sessanta 99, 47899 \\ Dogana, Republic of San Marino
}

\begin{abstract}
An experimental investigation on the mechanical performance of epoxy-coated Alkali-Resistant (AR) glass textile reinforced mortar subjected to elevated temperature is presented. Two epoxy coatings are considered, which differ by the hardening agent alone. After 56 days dry curing, specimens are heated up to four different temperatures. After cooling down to ambient temperature, specimens are assessed in uni-axial tensile test according to Annex A of AC434. First cracking strength and elongation, ultimate tensile strength and elongation, cracked and uncracked moduli, transition point location and energy dissipation capability are evaluated. It is found that, in the explored temperature range, degradation is surprisingly mild and strongly dependent on the resin which is taken as coating agent. Indeed, temperature exposure may lead to strength enhancement. This positive outcome takes place at the expense of ductility and it is traced back, through Differential Scanning Calorimetry (DSC), to a postcuring process. Nonetheless, energy dissipation still decreases with temperature and, remarkably, with the same power-law behaviour for both resins. Such behaviour is compatible with a cumulative Weibull distribution, that is adopted in thermal damage models for resins, and it indicates that the underlying damage mechanism indeed operates on the resin at the fabric-to-matrix interface.
\end{abstract}

\footnotetext{
* Corresponding author

Email address: cesare.signorini@unimore.it (Cesare Signorini)
} 
Keywords: TRM, High temperature, Epoxy coating

\section{Introduction}

The possibility of high temperature exposure poses a serious limitation to the applicability of organic matrix reinforcing systems, such as fibre-reinforced polymers (FRPs). Indeed, exposing FRP systems to temperatures in excess of or even close to the glass transition temperature $T_{g}$ produces a substantial and sudden drop in the mechanical response $[10,6]$. This behaviour, that rapidly leads to delamination and failure, is all the more undesired in consideration of the fairly low transition temperature $T_{g} \approx 80^{\circ} \mathrm{C}$ characterizing most organic resins. In this respect, Textile Reinforced Mortar/Cement (TRM/TRC) and Fabric Reinforced Cementitious Matrix (FRCM) composite materials exhibit vastly superior thermal stability, in light of the adoption of an inorganic matrix. On the other hand, the bond strength between the fabric and the inorganic matrix is generally weak and this leads to poor mechanical performance and a generally inconsistent failure pattern $[2,21]$. Improvement in the matrix-tofabric bond may be obtained by adopting inorganic $[13,31]$ or organic $[29,9,19]$ coatings. Consequently, investigation of the effect of temperature exposure on TRM is complicated by the need to consider the whole composite package, which consists of the matrix, the fabric and the coating.

A large body of literature is devoted to the characterization of FRP systems subjected to elevated temperature, see, for instance, $[10,7,4,28,16,15]$ and references therein. Conversely, a limited number of studies is available concerning the effect of high temperature exposure on TRM and FRCM and these are mainly focused on carbon and PBO fabrics [24,34]. In this framework, a crucial issue that requires careful investigation is the role played by high temperature exposure on the adhesive behaviour of the laminates at the mortar-to-substrate interphase, as discussed by Ombres [23] and Maroudas and Papanicolaou [18] for concrete and masonry structures, respectively. The former study presents single-lap shear tests on PBO-FRCM laminates applied on concrete supports 
and reports that conditioning at $50{ }^{\circ} \mathrm{C}$ and $100^{\circ} \mathrm{C}$ affects not only the loadbearing capacity of the composite, which decreases from 25 to $40 \%$ depending on the number of layers, but also the failure and the delamination modes. Indeed, failure statistically changes from matrix-to-fabric slippage for the unconditioned samples to debonding at matrix-to-concrete interphase for the conditioned ones. Analogously, in the contribution by Maroudas and Papanicolaou [18], single-lap shear tests are conducted on G-TRM thin laminates applied to brick panels and exposed to temperatures up to $300^{\circ} \mathrm{C}$. It is shown that, if the temperature exceeds $100{ }^{\circ} \mathrm{C}$, failure is mainly triggered by adhesive debonding at the masonry-to-mortar interphase and strongly affected by the deterioration of the ultimate strength of the bare glass fabric. Furthermore, Raoof and Bournas [26] and Bisby et al. [3] assess the response in bending of TRM and FRP reinforcing systems subjected to high temperatures, while Tetta and Bournas [32] considers jacketing. Trapko [33] compares FRP and FRCM confined concrete elements exposed to temperatures up to $80^{\circ} \mathrm{C}$ for $24 \mathrm{~h}$. Already at $40^{\circ} \mathrm{C}$ compressive strength of FRP jacketed elements is reduced by $20 \%$ and at $80^{\circ} \mathrm{C}$ ductility drops by 50\%, as opposed to a 11\% loss encountered for FRCM. de Andrade et al. [8] investigate double-sided pull-out strength of an epoxy coated carbon yarn after $120 \mathrm{~min}$ exposure at $100^{\circ} \mathrm{C}, 150{ }^{\circ} \mathrm{C}, 200^{\circ} \mathrm{C}, 400^{\circ} \mathrm{C}$ and $600^{\circ} \mathrm{C}$. Maximum pull-out force and pull-out work are computed and compared with the dry yarn. Interestingly, an increase in mechanical performance of the coated specimens is observed after heating at temperatures up to $150^{\circ} \mathrm{C}$, that is ascribed to a "polymer interlocking mechanism in the yarn-matrix interface, which is generated during the heating and cooling of the polymer yarn coating". In Rambo et al. [25], uni-axial tensile tests of basalt textile reinforced plates are conducted. The basalt fabric is coated with styrene-acrylic latex and refractory concrete is adopted as matrix. Plates are exposed for $60 \mathrm{~min}$ at temperatures in the range $75-1000^{\circ} \mathrm{C}$. It is found that performance loss is mild up to $200^{\circ} \mathrm{C}$ and it is concluded that "the presence and the type of coating can become a deterministic factor in the tensile response of the composite submitted to elevated temperatures". Recently, Donnini et al. [9] present experimental and numeri- 
cal results on the mechanical performance of dry and epoxy-plus-sand coated carbon FRCM composites under uni-axial tension and double-shear bond test. Beside ambient temperature, $120 \mathrm{~min}$ exposure at $80^{\circ} \mathrm{C}$ and at $120^{\circ} \mathrm{C}$ are considered. It is worth emphasizing that mechanical tests are carried out inside the climatic chamber, where specimens are exposed at high temperature. An impressive $70 \%$ drop in the ultimate tensile strength (and a $54 \%$ elongation loss) is determined with respect to the ambient condition already at $80^{\circ} \mathrm{C}$.

In general, the existing literature lacks from detailing the thermo-physical properties of the coating agent, that is usually adopted taking an out-of-thebox approach. In this work, we focus on the role of epoxy coating on the thermal deterioration of the matrix-to-fabric interface. To this aim, the same pair of epoxy resins considered in [19] are adopted, which differ only by the hardening agent. This feature, however, leads to important differences in terms of thermo-physical properties that exert a profound influence on the behaviour upon high temperature exposure [12]. To avoid degradation of the lime mortar and restrict attention to the epoxy coating, temperature exposure is limited in the range $20-250{ }^{\circ} \mathrm{C}$ and 56 -day dry curing is adopted. Mechanical performance is assessed in uni-axial traction of rectangular coupons according to Annex A of the guidelines [14]. DSC analysis supports the conclusion that, depending on the resin formulation, high temperature exposure may benefit strength (at the expense of ductility), inasmuch as it promotes cross-linking in a post-curing process. This mechanism is likely to explain the outcome of the double pull-out tests carried out in [8] and of the uni-axial traction of plates described in [25].

\section{Materials and methods}

\subsection{Materials}

\subsubsection{Reinforcing fabric and inorganic matrix}

The commercially available Alkali Resistant Glass (ARG) fabric Zirconglass Wire ${ }^{\circledR}$ RV320-AR (Fibre Net Spa) is adopted as fabric reinforcement. This is a balanced bi-axial open-squared mesh whose $19 \%$ weight content of Zirconium Oxide $\left(\mathrm{ZrO}_{2}\right)$ imparts resistance to the alkaline mortar environment. The main 
Table 1: ARG Fabric mechanical properties $($ tex $=\mathrm{g} / \mathrm{km})$

\begin{tabular}{lcc}
\hline Characteristic & Unit & Value \\
\hline Yarn count & tex & 1200 \\
Net specific weight per unit fabric area & $\mathrm{g} / \mathrm{mm}^{2}$ & 300 \\
Fabric specific weight & $\mathrm{g} / \mathrm{cm}^{3}$ & 2.50 \\
Grid spacing (square grid) & $\mathrm{mm}$ & 12 \\
Equivalent thickness, $t_{f}$ & $\mathrm{~mm}$ & 0.06 \\
Ultimate strength along warp (with epoxy) & $\mathrm{MPa}$ & 1200 \\
Ultimate elongation along warp & $\mathrm{mstrain}$ & 20 \\
Elastic modulus & $\mathrm{GPa}$ & 74 \\
\hline
\end{tabular}

Table 2: Mortar properties

\begin{tabular}{lcc}
\hline Characteristic & Unit & Value \\
\hline Nominal setting water content & $\%$ & 21.2 \\
Final density & $\mathrm{g} / \mathrm{cm}^{3}$ & 1.58 \\
Min. compression strength after 28 days & $\mathrm{MPa}$ & 15.0 \\
Min. flexural strength after 28 days (EN 196/1) & $\mathrm{MPa}$ & 5.0 \\
Min. support adhesion strength after 28 days & $\mathrm{MPa}$ & 1.0 \\
Aggregate maximum size & $\mathrm{mm}$ & 1.4 \\
Compression elastic modulus (EN 13412) & $\mathrm{GPa}$ & 9.0 \\
\hline
\end{tabular}

89 properties of the fabric, as given by the manufacturer, are collected in Table 1.

90 A pre-mixed natural hydraulic lime (NHL) mortar GeoCalce Fino $\left.{ }^{(}\right)$(Kerakoll

${ }_{91} \mathrm{SpA}$ ), aimed at structural purposes, constitutes the inorganic embedding matrix.

92 Table 2 gathers the main properties of this fine-grained repair mortar as given

93 by the manufacturer.

\subsubsection{Fabric sizing and coating}

ARG fabric is subjected, as received, to a preliminary sizing treatment to enhance chemical compatibility with the epoxy coating. Following the procedure

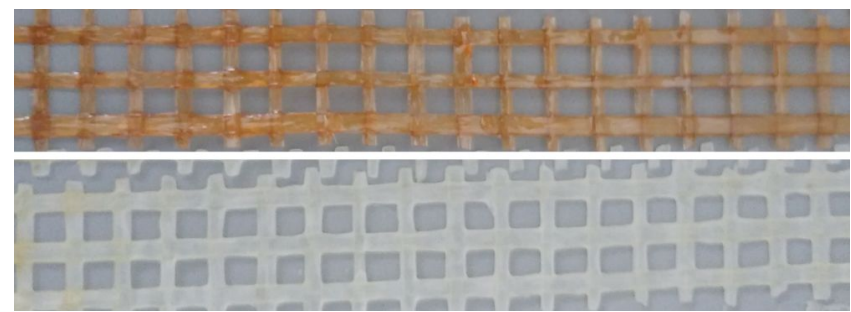

Figure 1: Coated fabric before the heat treatment (upper: ER, lower: EW) 
Table 3: Hardening agents datasheet

\begin{tabular}{lccc}
\hline Characteristic & Unit & m-PDA & DETA \\
\hline Physical form & - & Pellets & Liquid \\
Formula & - & $\mathrm{C}_{6} \mathrm{H}_{8} \mathrm{~N}_{2}$ & $\mathrm{C}_{4} \mathrm{H}_{13} \mathrm{~N}_{3}$ \\
Melting point & ${ }^{\circ} \mathrm{C}$ & $63 \div 65$ & -40 \\
Flash point & ${ }^{\circ} \mathrm{C}$ & 175 & 94 \\
Boiling point & ${ }^{\circ} \mathrm{C}$ & $282 \div 284$ & $200 \div 204$ \\
\hline
\end{tabular}

described in [19], fabric is functionalized by immersion in a $2 \%$ vol. aqueous solution of (3-Aminopropyl)triethoxysilane (99\%, Sigma-Aldrich), which takes on the role of coupling agent. Care is taken to avoid organic solvents which may damage the thermoplastic stitches that hold the unwoven fabric. Fabric is then dried in ambient air. Fabric epoxy coating is obtained from high-purity bisphenol A diglycidylether resin D.E.R. 332, (DOW Chemicals, hereafter "DER"). Two coatings are considered, named ER and EW, which only differ by the curing agent: ER exploits the aromatic hardener m-phenylenediamine (99\%, Acros Organics hereafter "m-PDA"), while EW adopts the aliphatic diethylenetriamine (99\%, Alfa-Aesar hereafter "DETA"). Table 3 presents the main characteristics of the curing agents as declared by the producers, with particular emphasis on thermal properties. The coated fabric is laid on a polypropylene sheet to prevent warping, which may hinder the lamination process, and then it is allowed to set for 7 days at laboratory conditions (Fig.1).

\subsubsection{Specimen manufacturing}

1-ply ARG-TRM coupons are manufactured on an individual basis by means of a dismountable polyethylene formwork, following a well-established and reliable manufacturing protocol, see $[30,22]$. The lubricated surface of the formwork is segmented by $3 \mathrm{~mm}$-thick laths, equally spaced according to the specimen width. In between adjacent laths, uniformly-thick mortar layers are laid out. Indeed, the top surface of the laths provides an easy reference for scraping off the mortar in excess of $3 \mathrm{~mm}$. Cut-to-size glass fabric is laid on top of the fresh mortar and gently pressed on it. Then, a second array of polyethylene laths is pinned on top of the first to provide reliable fabric placing as well as reference 


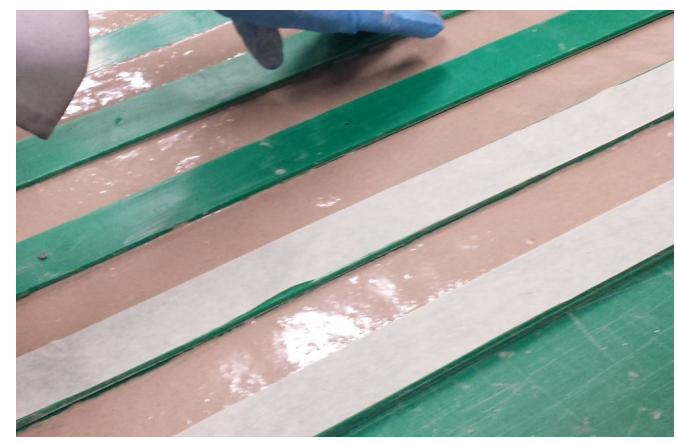

Figure 2: Manufacturing process of the specimens: application of the second set of constraining laths for uniform placement of the second layer of mortar
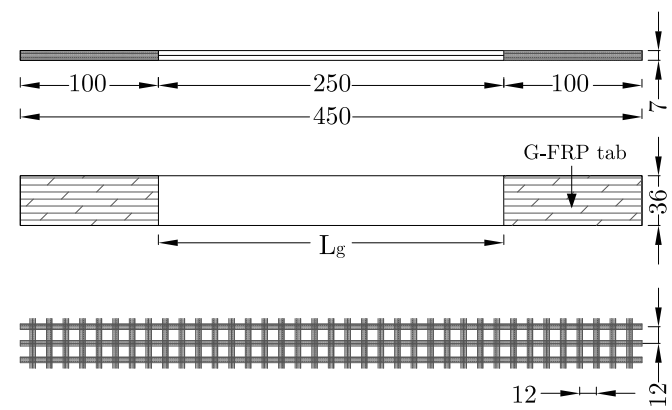

Figure 3: Coupon and fabric mesh geometries

for laying out the second mortar layer (Figure 2). At the final stage of their placing, laths are covered with paper adhesive tape to ease specimen stripping. A minimum of four specimens is considered for each test group. 7-day moist curing is followed by dry curing at room temperature for 56 days in total. Indeed, curing time is proven to deeply affect the mechanical performance of lime and cement-based composites [22] and their resistance to aggressive environments [20]. The specimen geometry (coupon) is schematically drawn in Fig.3 alongside the fabric mesh size. After heating and natural cooling, a pair of externally bonded 100-mm G-FRP tabs is glued at both ends of each specimen to accommodate the clamps of the testing machine. 
Table 4: High temperature exposure conditions in the literature

\begin{tabular}{|c|c|c|c|c|}
\hline Ref. & Temp. $\left[{ }^{\circ} \mathrm{C}\right]$ & $\begin{array}{l}\text { Exp. } \\
\text { time } \\
{[\min ]}\end{array}$ & Composite & Test \\
\hline Xu et al. [34] & 120,200 & 30,90 & CFRCM+epoxy & \multirow{4}{*}{$\begin{array}{l}\text { 3-point bending } \\
\text { uni-axial traction, } \\
\text { double shear bond } \\
\text { double sided pull- } \\
\text { out } \\
\text { compression of con- } \\
\text { fined cylinders }\end{array}$} \\
\hline Donnini et al. [9] & $20,80,120$ & 100 & CFRCM+epoxy & \\
\hline de Andrade et al. [8] & $\begin{array}{l}100, \quad 150 \\
200,400,600\end{array}$ & 120 & CFRCM+epoxy & \\
\hline Trapko [33] & $40,60,80$ & 1440 & CFRCM & \\
\hline Rambo et al. [25] & $\begin{array}{l}75,150,200 \\
300, \quad 400 \\
600,1000\end{array}$ & 60 & basalt+latex+FRCM & traction of plates \\
\hline Ombres [23] & $20,50,100$ & 480 & PBO-FRCM & \multirow{3}{*}{$\begin{array}{l}\text { single-lap shear } \\
\text { compression on } \\
\text { confined cylinders } \\
\text { single-lap shear }\end{array}$} \\
\hline Ombres [24] & $\begin{array}{l}20,50, \quad 100 \\
150,200,250\end{array}$ & 1200 & PBO-FRCM & \\
\hline $\begin{array}{l}\text { Maroudas and Papani- } \\
\text { colaou [18] }\end{array}$ & $\begin{array}{l}20,100,200 \\
300\end{array}$ & 1200 & GFRCM & \\
\hline
\end{tabular}

\subsection{High temperature exposure}

After curing, coupons undergo a heating treatment in a Binder WTC oven. A $4{ }^{\circ} \mathrm{C} / \mathrm{min}$ heating ramp is applied until either of four different target temperatures is reached, namely $100,150,200$ or $250^{\circ} \mathrm{C}$. The set of target temperatures is chosen to induce coating degradation only. Indeed, according to [5], fabric composites in a cement-based matrix perform well up to $450^{\circ} \mathrm{C}$. Once the target temperature is attained, isothermal conditions are maintained for $120 \mathrm{~min}$. It should be observed that heating time and target temperature are not standard and indeed they vary greatly across the relevant literature, as summarized in Tab.4. Specimens are then moved to room temperature $\left(20 \pm 2^{\circ} \mathrm{C}\right)$ and left to cool down in a natural cooling process, as in [8].

\section{Experimental characterization}

\subsection{Optical investigation}

Preliminary visual investigation of the specimens after heating is illustrated in Fig.4. In particular, both epoxy coatings, when exposed to temperatures 


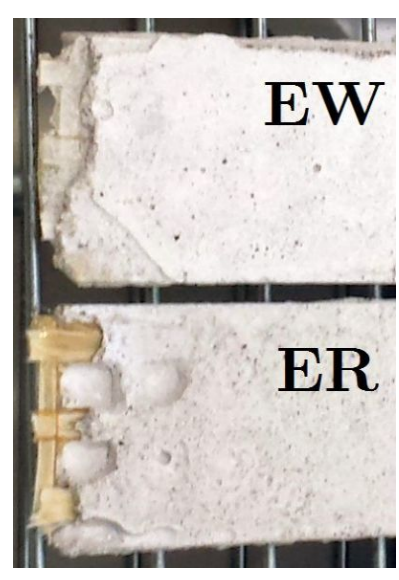

(a) $150^{\circ} \mathrm{C}$

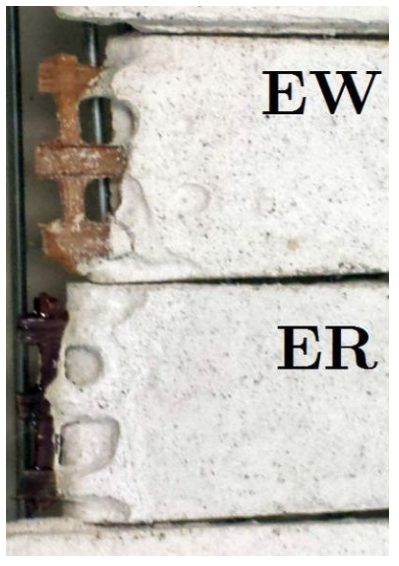

(b) $200^{\circ} \mathrm{C}$

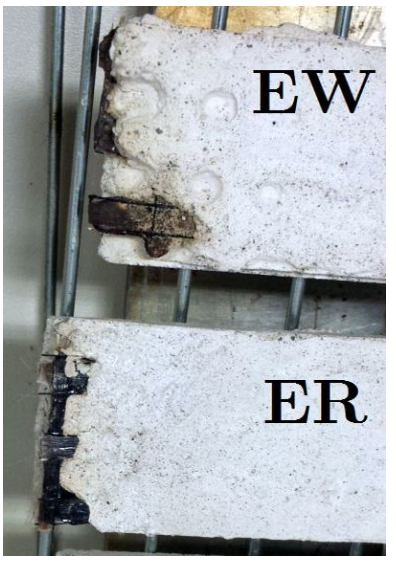

(c) $250^{\circ} \mathrm{C}$

Figure 4: Mortar and fabric after temperature exposure: it clearly appears that both epoxy coatings oxidise above $150^{\circ} \mathrm{C}$

higher than $150{ }^{\circ} \mathrm{C}$, appear oxidized and blackened (compare with the uncoated fabric shown in Fig.1), while little to no effect is visible at lower temperature. Mortar appears unaffected by any temperature.

\subsection{Differential Scanning Calorimetry}

A Differential Scanning Calorimetry (DSC) analysis (TA DSC 2010, TA Instruments, New Castle, DE, USA) is performed on both epoxy resins, EW and $\mathrm{ER}$, in a single heating ramp, starting from $0{ }^{\circ} \mathrm{C}$ up to $250^{\circ} \mathrm{C}$, with a heating rate of $10^{\circ} \mathrm{C} / \mathrm{min}$, under nitrogen flow. The analysis is conducted at two different stages, namely immediately after resin preparation ("as mixed" condition) and after two-week curing at ambient temperature. Comparing the heating enthalpy developed in the two conditions yields the conversion degree, that measures the extent to which cross-linking may occur at ambient temperature.

\subsection{Uni-axial monotonic tensile test}

Following the guidelines [14], mechanical performance is assessed in uniaxial tensile test. A Instron 5567 electromechanical Universal Testing Machine (UTM) is employed. The UTM is equipped with a $30 \mathrm{kN}$ load cell and a pair of wedge clamps which, as specified in [14, §A2.2], "shall apply sufficient lateral 


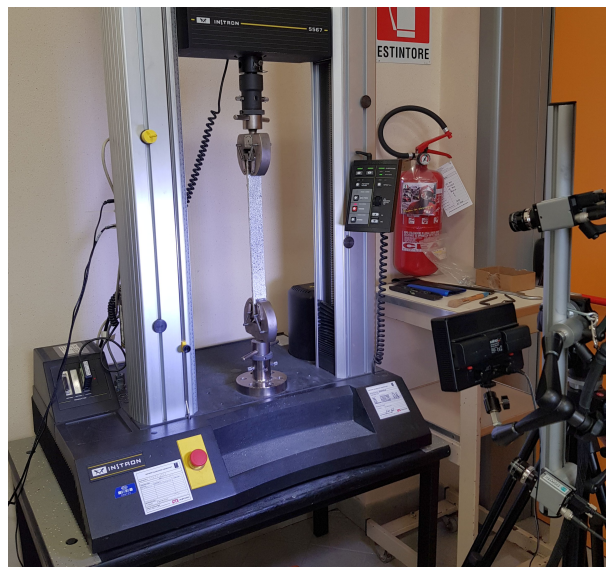

Figure 5: Uni-axial tensile test set-up with DIC monitoring of the speckled specimen

pressure to prevent slippage between the grip face and the coupon". Besides, rotationally self-aligning grips are adopted, "to minimize bending stresses in the coupon". Tests are performed under displacement control at a nominal displacement rate of $0.5 \mathrm{~mm} / \mathrm{min}$, that complies with the elongation rate proposed by the RILEM committee [27].

As already pointed out in [20], for the correct determination of elastic moduli, transition points and of the strain evolution during testing, the sliding displacement occurring in the wedge clamps needs to be subtracted from the nominal elongation ramp. To this aim, a Dantec Dynamics Q400 Digital Image Correlation (DIC) system is employed to measure the actual specimen displacement. Indeed, comparison of the nominal data with the DIC-measured elongation reveals a $8 \div 10 \%$ discrepancy in strain evaluation. The test set-up is shown in Fig.5.

\section{Results}

\subsection{Mechanical performance}

Fig.6 presents the mean strength curve for all test groups. As customary, strength is reported to the coated fabric cross-section and strain is normalized against the gauge length $L_{g}$. It immediately appears that the EW group performance is significantly impaired by the heating conditioning at any temperature, 


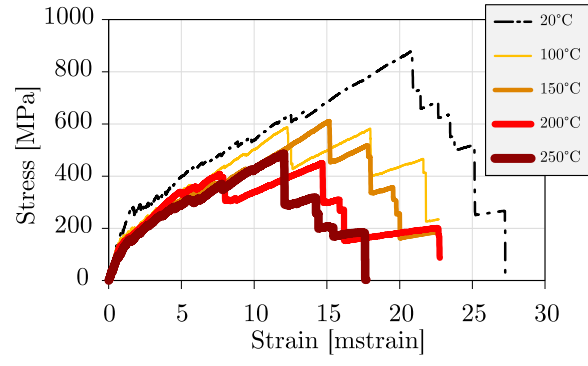

(a) EW groups

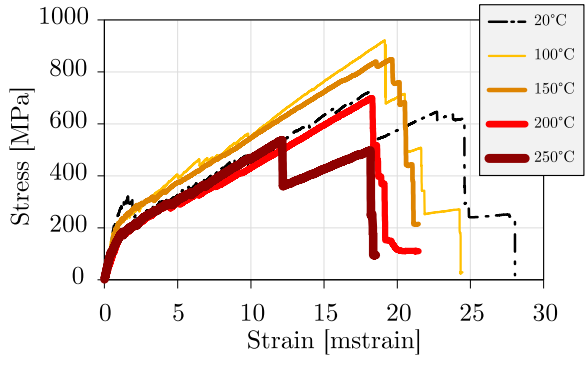

(b) ER groups

Figure 6: Mean stress-strain curve for the control (black, dashed-dotted line) and the exposed groups (solid lines with increasing thickness in dependence of the temperature exposure), namely $100{ }^{\circ} \mathrm{C}$ (yellow), $150{ }^{\circ} \mathrm{C}$ (orange), $200^{\circ} \mathrm{C}$ (red) and $250^{\circ} \mathrm{C}$ (amaranth)

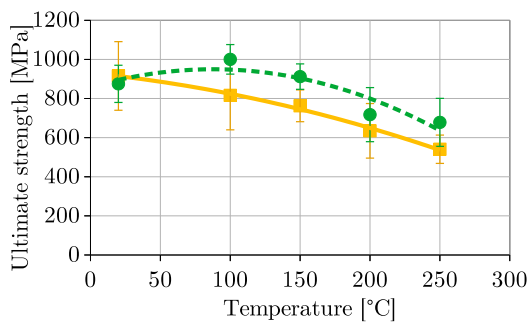

Figure 7: Mean ultimate tensile strength as a function of the exposure temperature for ER (circles, green) and EW (squares, yellow). \pm 1 standard deviation bars and parabolic curve-fits are also presented 
Table 5: Mean first cracking strength (FCS), ultimate tensile strength (UTS), uncracked and cracked moduli for the EW group as a function of the exposure temperature. $C V$ is the coefficient of variation

\begin{tabular}{c|cc|cc|cc|cc}
\hline $\mathbf{T}$ & \multicolumn{2}{|c|}{$\mathbf{F C S}$} & \multicolumn{2}{|c|}{$\mathbf{U T S}$} & $E^{*}$ & \multicolumn{2}{|c}{$E_{f}$} \\
{$\left[{ }^{\circ} \mathrm{C}\right]$} & $\mu\left(f_{c r}\right)$ & $\mathrm{CV}$ & $\mu\left(f_{u}\right)$ & $\mathrm{CV}$ & $\mu\left(E_{f}^{*}\right)$ & $\mathrm{CV}$ & $\mu\left(E_{f}\right)$ & $\mathrm{CV}$ \\
& {$[\mathrm{MPa}]$} & {$[\%]$} & {$[\mathrm{MPa}]$} & {$[\%]$} & {$[\mathrm{GPa}]$} & {$[\%]$} & {$[\mathrm{GPa}]$} & {$[\%]$} \\
\hline 20 & 271.0 & 23.1 & 915.6 & 19.2 & 249.7 & 20.5 & 30.8 & 23.1 \\
100 & 163.1 & 14.0 & 816.3 & 21.6 & 190.9 & 12.6 & 37.4 & 14.0 \\
150 & 154.2 & 15.0 & 762.7 & 10.7 & 193.8 & 38.1 & 34.7 & 1.5 \\
200 & 165.1 & 42.0 & 634.8 & 22.0 & 162.8 & 21.7 & 39.0 & 42.0 \\
250 & 168.8 & 51.2 & 540.7 & 13.4 & 160.8 & 41.0 & 29.8 & 51.8 \\
\hline
\end{tabular}

Table 6: Mean first cracking strength (FCS), ultimate tensile strength (UTS), uncracked and cracked moduli for the ER group as a function of the exposure temperature. $C V$ is the coefficient of variation

\begin{tabular}{c|cc|cc|cc|cc}
\hline $\mathbf{T}$ & \multicolumn{2}{|c|}{ FCS } & \multicolumn{2}{|c|}{$\mathbf{U T S}$} & \multicolumn{2}{|c|}{$E_{f}^{*}$} & \multicolumn{2}{|c}{$E_{f}$} \\
{$\left[{ }^{\circ} \mathrm{C}\right]$} & $\mu\left(f_{c r}\right)$ & $\mathrm{CV}$ & $\mu\left(f_{u}\right)$ & $\mathrm{CV}$ & $\mu\left(E_{f}^{*}\right)$ & $\mathrm{CV}$ & $\mu\left(E_{f}\right)$ & $\mathrm{CV}$ \\
& {$[\mathrm{MPa}]$} & {$[\%]$} & {$[\mathrm{MPa}]$} & {$[\%]$} & {$[\mathrm{GPa}]$} & {$[\%]$} & {$[\mathrm{GPa}]$} & {$[\%]$} \\
\hline 20 & 192.4 & 24.4 & 875.0 & 10.9 & 319.7 & 21.1 & 31.0 & 15.0 \\
100 & 183.3 & 16.4 & 1000.3 & 7.6 & 286.1 & 18.6 & 40.1 & 7.2 \\
150 & 225.5 & 5.9 & 912.0 & 7.1 & 250.9 & 10.1 & 35.3 & 10.2 \\
200 & 135.4 & 30.3 & 717.6 & 19.3 & 156.4 & 1.8 & 32.4 & 22.2 \\
250 & 124.5 & 29.5 & 678.0 & 18.1 & 187.4 & 18.7 & 37.2 & 6.8 \\
\hline
\end{tabular}

while the ER groups exhibit a mixed response. Results in terms of first cracking strength, ultimate tensile strength (UTS), cracked and uncracked moduli are summarized in Tab.5 for EW and in Tab.6 for ER. This behaviour is better illustrated by the curves of Fig.7, which compare the mean ultimate tensile strength (UTS) across the two groups. Indeed, while the mean UTS across the EW group decreases monotonically with the exposure temperature, it increases significantly in the ER-100 group and marginally in the ER-150 group, before it starts to decay. Data scattering for elastic moduli is presented in Fig.8 as a function of the conditioning temperature. Parabolic curve-fitting shows that scattering decreases upon temperature exposure up to a critical temperature that is connected to a post-curing phenomenon, as discussed in Sect.4.2.

In general, even for EW, heat conditioning has a surprisingly limited effect on the performance decay of the coated fabric, especially when results are compared 


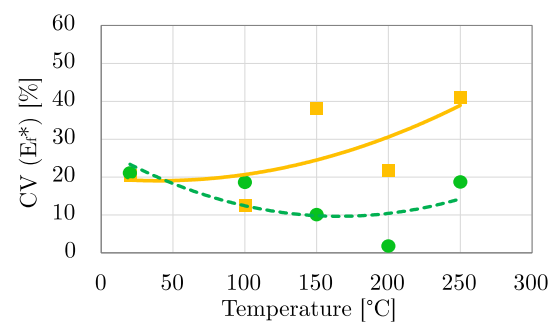

(a) $E_{f}^{*}$

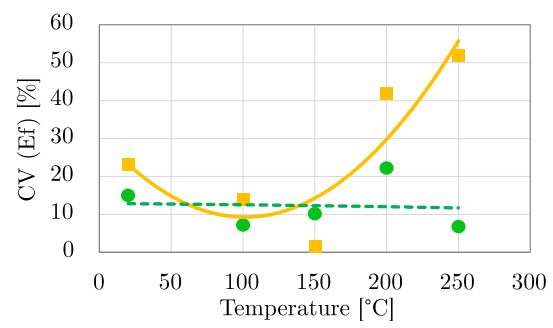

(b) $E_{f}$

Figure 8: Coefficient of Variance (CV) for the uncracked (a) and cracked (b) secant moduli as a function of the exposure temperature for EW (orange) and ER (green) alongside its parabolic curve-fit. It is seen that post-curing positively affects data scattering as well as absolute performance

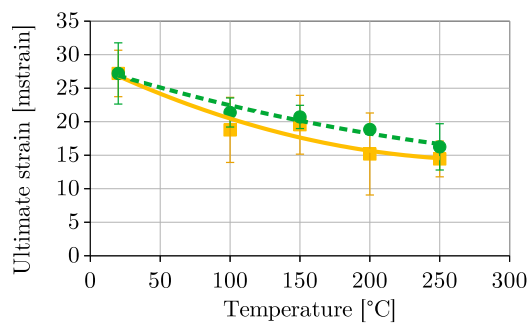

Figure 9: Mean ultimate strain values as a function of the exposure temperature for ER (circles, green) and EW (squares, yellow). \pm 1 standard deviation bars and parabolic curvefits are also presented

with the existing literature. In fact, although the performance pattern of ER is similar to that observed in [8, Fig.5] in the context of a double-sided pull-out test of a epoxy coated carbon multi-filament yarn, it should be remarked that, in the absence of a DSC analysis, the polymer coating adopted there seems exceptionally thermostable, for it cross-links at $160{ }^{\circ} \mathrm{C}$ and "the polymer film remained stable at temperatures up to $200{ }^{\circ} \mathrm{C}$ ".

Fig.9 presents a similar comparison of the mean ultimate strain at failure and it shows that ductility decreases with temperature through a similar trend for both coatings.

\subsection{Thermal analysis}

The DSC analysis reveals an exothermic peak for both resins, associated to two-week post-curing in ambient conditions. In order to estimate the con- 
Table 7: Specific enthalpy associated to curing $\left(H_{\text {curing }}\right)$ of as-mixed and two-week-cured $\mathrm{EW}$ and ER resins and corresponding conversion degree.

\begin{tabular}{|c|c|c|c|}
\hline \multirow{2}{*}{ Resin } & \multicolumn{2}{|c|}{$H_{\text {curing }}[\mathrm{J} / \mathrm{g}]$} & \multirow{2}{*}{$\begin{array}{c}\text { Conversion degree } \\
{[\%]}\end{array}$} \\
\hline & as mixed & two-week cured & \\
\hline EW & 387 & 15 & 96 \\
\hline ER & 379 & 123 & 67 \\
\hline
\end{tabular}

version degree that could be achieved, the specific enthalpy measured from the DSC thermograms of Fig.10 in the two-week-cured group is compared to the corresponding value obtained in the "as-mixed" group, as summarized in Table 7. For EW, the specific enthalpy associated to curing is located at $387 \mathrm{~J} / \mathrm{g}$ in the as-mixed condition and plunges to $15 \mathrm{~J} / \mathrm{g}$ (corresponding to less than $4 \%$ ) after two-week curing at ambient temperature. Consequently, two-week curing lends a conversion degree of about $96 \%$ when DETA is employed as curing agent. The same procedure applied to ER (that is when m-PDA acts as curing agent) reveals that the conversion degree achieved after two week curing at ambient temperature is much lower: about $67 \%$. In fact, aliphatic amines allow curing at room temperature, whereas aromatic amines usually require a high-temperature treatment to achieve full conversion. However, aromatic amine-cured systems can be applied at temperatures sensibly higher than those which are compatible with aliphatic amine-cured resins [12, p.168]. The completion of the curing process and the high thermal stability that is typical of amine-cured epoxy resins are likely responsible for the increase in mechanical properties (elastic modulus and strength) that is observed in the epoxy-coated G-TRM composite materials that were treated at temperatures not exceeding $150{ }^{\circ} \mathrm{C}$. At higher temperature, degradative phenomena are likely to outweigh the benefit conveyed by post-curing.

\subsection{Failure analysis}

Fig.11 illustrates progression to the two typical failure modes: either fabric rapture (a) or fabric slippage inside the matrix (b). Although, generally, both of them occur in mixed proportion in all test groups, fabric failure is far more 


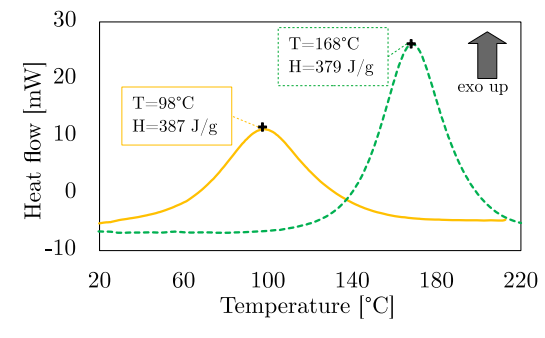

(a) Resins " as mixed"

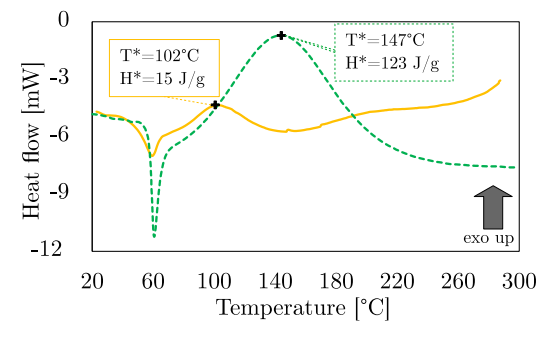

(b) Two-week cured resins

Figure 10: Differential scanning calorimetry (DSC) of EW resin (solid, yellow) and ER resin (dashed, green) right after mixing (a) and after two-week curing (b)
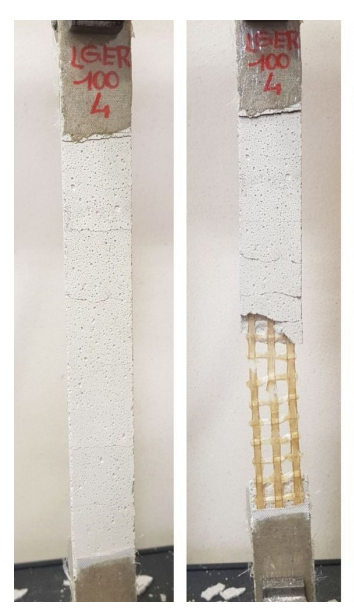

(a) Fabric failure

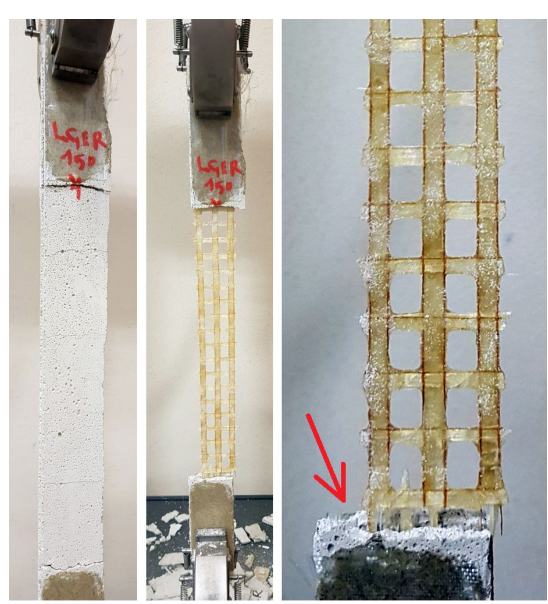

(b) Fabric slippage within the matrix and near the clamps

Figure 11: Typical failure modes observed for all groups 

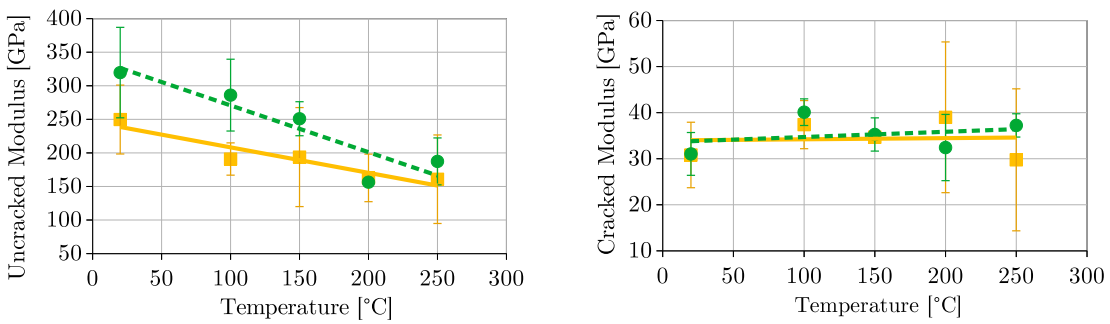

Figure 12: Uncracked (left) and cracked (right) modulus as a function of the exposure temperature for ER (circles, green) and EW (squares, yellow). \pm 1 standard deviation bands and linear curve-fits are also given

frequent in the control group, while fabric slippage prevails in the specimens exposed to high temperature.

\section{Discussion}

Fig.12 illustrates the effect of temperature on the uncracked modulus $E_{f}^{*}$ and on the cracked modulus $E_{f}$ in the EW and in the ER group (see $[14,1]$ for the details of moduli definition and evaluation). It may be observed that temperature exposure strongly impairs the uncracked modulus $E_{f}^{*}$, while the cracked modulus $E_{f}$ remains statistically unaltered. This is compatible with the expectation that temperature affects the coating performance, whose bearing is mostly relevant when the matrix is still collaborating with the fabric and thereby uncracked. Furthermore, although ER coating performs significantly better than EW, line fitting suggests that this advantage decreases with temperature until equal performance is met at $T=250{ }^{\circ} \mathrm{C}$. Conversely, the cracked modulus $E_{f}$ reflects the modulus of the glass fabric, which is little affected by temperature. In fact, the cracked modulus is about the same across all groups.

Transition points (TPs) conventionally mark a sudden stiffness loss and a regime shift, in light of the fact that the cracked matrix ceases to contribute to the composite rigidity. Their location is shown in Fig.13 at different temperatures. This figure indicates that the transition stress nearly halves on high temperature exposure, irrespectively of the temperature value, in the EW group. Conversely, the ER group presents a similar transition point location for ER-100 


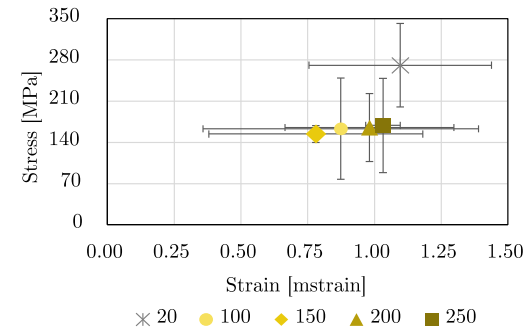

(a) EW group

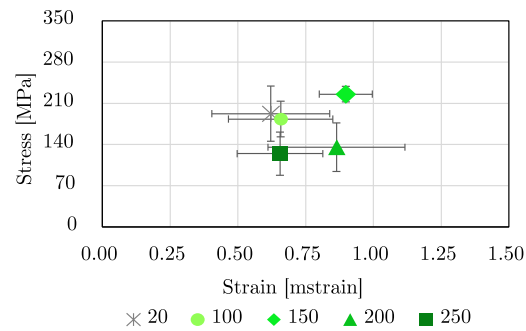

(b) ER group

Figure 13: Mean transition point location and \pm 1 standard deviation bars as a function of temperature for all test groups

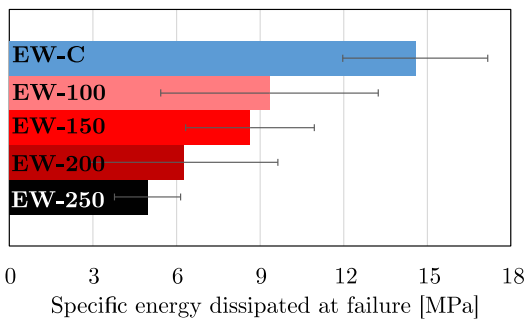

(a) EW groups

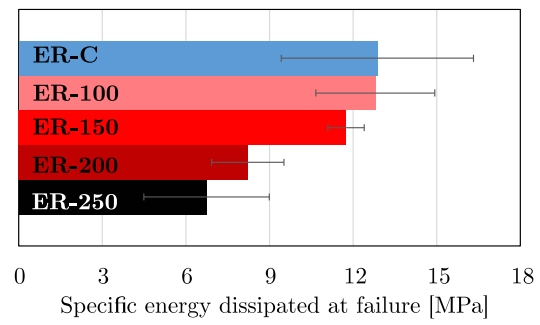

(b) ER groups

Figure 14: Mean specific energy dissipated at failure $W$ and \pm 1 standard deviation bars for the control $\left(\mathrm{C}\right.$, blue) and the heat treated groups at $100^{\circ} \mathrm{C}$ (light red), $150{ }^{\circ} \mathrm{C}$ (red), $200^{\circ} \mathrm{C}$ (dark red) and $250^{\circ} \mathrm{C}$ (black).

and, remarkably, higher transition stress and strain for ER-150, with respect to the control group. Temperature adverse influence starts to manifest itself at $200{ }^{\circ} \mathrm{C}$, when stress is impaired $(-37.5 \%)$ and yet strain is still higher than in the control group. Finally, at $250^{\circ} \mathrm{C}$, strain drops and it reaches the value for the control group. It is concluded that temperature generally decreases transition stress but it may improve transition strain.

Comparison in terms of specific (per unit fabric volume) dissipated energy $W$ is carried out in Fig.14. It appears that high temperature impairs energy dissipation in all test groups, with the possible exception of ER-100 which behaves similarly to the relevant control group. Remarkably, both coatings decay with an almost identical power-law rule, as illustrated in Fig.15 in terms of normalized quantities with respect to the ambient conditions. This finding is 


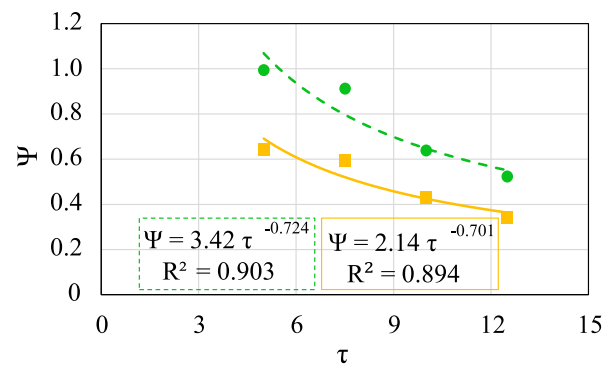

Figure 15: Normalized specific energy dissipated at failure $\Psi=W / W_{0}$ against normalized exposure temperature $\tau=T / T_{0}$ for ER (circles, green) and EW (squares, yellow) and powerlaw curve fit. $T_{0}=20^{\circ} \mathrm{C}$ is the ambient temperature and $W_{0}=W\left(T_{0}\right)$ is the corresponding dissipated energy.

compatible with a cumulative Weibull distribution for the relaxing and breaking of the intermolecular bonds in the resin, as described in the model proposed by Mahieux et al. [17], and it suggests that mechanical performance is indeed impaired by the mechanism of resin degradation. Conversely, hyperbolic tangent models, as in [11, Eq.(5)], do not seem to fit well experimental data.

Fig.16 presents the behaviour of the relative ductility across all test groups against temperature at different fraction of the UTS. Relative ductility is expressed as the ratio of the mean group strain $\epsilon_{i}(f), i \in\{\mathrm{ER}, \mathrm{EW}\}$ over the mean control group strain $\epsilon_{C}(f)$, when specimens are subjected to a traction force $f$ which is a fraction of $f_{u_{i}}, i \in\{\mathrm{ER}, \mathrm{EW}\}$, that is the UTS for the relevant group. It is clearly seen that the higher the temperature of conditioning, the more brittle specimens behave, with the single exception of $20 \%$ loading, see Fig.16(a). However, for any temperature and loading fraction, ER outperforms EW in a statistically significant manner. It is worth emphasizing that the EW group is connected to superior energy dissipation capability in the control group, as compared to the ER group. This advantage at ambient temperature can be traced back to the EW coating layer being significantly thinner [19]. Therefore, it may be argued that coating thickness is unfavourable in terms of ambient temperature mechanical performance, yet it is advantageous when high temperature exposure is envisaged. 


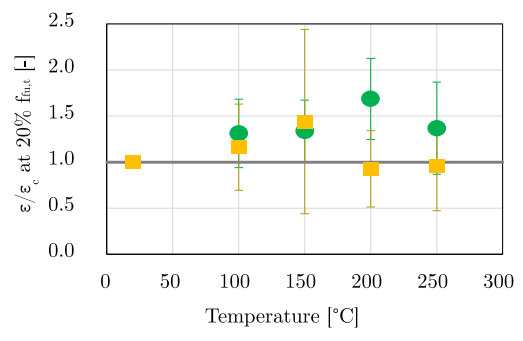

(a) $20 \%$ of UTS

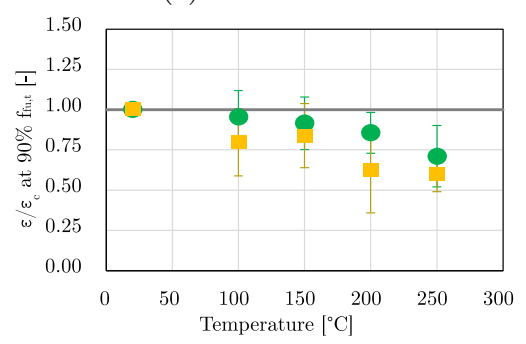

(c) $90 \%$ of UTS

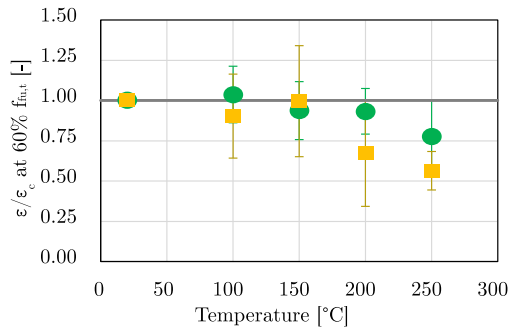

(b) $60 \%$ of UTS

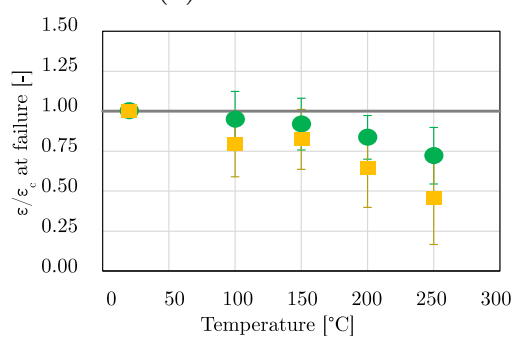

(d) $100 \%$ of UTS

Figure 16: Ratio of the group mean elongation $\epsilon$ to the relevant control group elongation $\epsilon_{C}$ at a fraction of the corresponding UTS as a function of temperature for ER (circles, green) and EW (squares, yellow)

\section{Conclusions}

This works reports on the influence of the epoxy coating thermo-physical properties on the mechanical performance of AR-glass textile reinforced mortar (TRM) after exposure to high temperature. As in [19], two epoxy coatings are considered, which differ by the hardening agent alone. Nonetheless, this difference brings about distinct thermo-physical properties. Since focus is set on the epoxy coating, exposure temperatures are limited to $250{ }^{\circ} \mathrm{C}$ to prevent thermal effects from extending to the lime mortar and, eventually, to the glass fabric. Mechanical performance is assessed according to AC434 through uniaxial tensile tests of rectangular coupons. The effect of temperature exposure in terms of first cracking strength and strain, ultimate strength and elongation, cracked and uncracked moduli, transition point location and energy dissipation capability is illustrated. It is found that temperature exposure may increase strength at the expense of ductility, and this outcome parallels similar findings 
obtained in the context of pull-out [8] and tensile [25] tests. DSC analysis reveals that temperature exposure may trigger competing processes: on the one side further cross-linking is favoured in a post-curing process, on the other side thermal degradation occurs. The final outcome strongly depends on the considered epoxy coating and its post-curing capability. Indeed, in contrast to the findings reported in [9], mild degradation is documented, especially when compared to FRP systems. Temperature induces a monotonic decay in the energy dissipation capability and, remarkably, the decay law, that is the same for both coatings, complies with a cumulative Weibull distribution (power-law rule). This behaviour is typical of models accounting for the relaxing and breaking of molecular bonds in resins, as in $[17,11]$. Therefore, this observation supports the understanding that the resin degradation mechanism at the fabric-to-matrix interface governs mechanical performance for both coatings.

\section{Acknowledgements}

The contribution of Dr. Jessica Morandi in specimen preparation is gratefully acknowledged.

\section{Funding}

AN gratefully acknowledges funding from "FAR Dipartimentali 2016", decr. $73 / 2017$, prot. 37510 .

\section{Declaration of interest}

Declarations of interest: none.

\section{Bibliography}

[1] D Arboleda. Fabric Reinforced Cementitious Matrix (FRCM) Composites for Infrastructure Strengthening and Rehabilitation: Characterization Methods. PhD thesis, University of Miami, 2014. Open Access Dissertation. Paper 1282. 
[2] A Badanoiu and J Holmgren. Cementitious composites reinforced with continuous carbon fibres for strengthening of concrete structures. Cement Concrete Comp, 25(3):387-394, 2003.

[3] L Bisby, T Stratford, C Hart, and S Farren. Fire performance of wellanchored TRM, FRCM and FRP flexural strengthening systems. In Adv Compos Constr, Queen's University Belfast, Sept. 2013.

[4] S Cao, WU Zhis, and X Wang. Tensile properties of CFRP and hybrid FRP composites at elevated temperatures. J Compos Mater, 43(4):315330, 2009.

[5] A Çavdar. A study on the effects of high temperature on mechanical properties of fiber reinforced cementitious composites. Compos Part B-Eng, 43 (5):2452-2463, 2012.

[6] EU Chowdhury, R Eedson, LA Bisby, MF Green, and N Benichou. Mechanical characterization of fibre reinforced polymers materials at high temperature. Fire Technol, 47(4):1063-1080, 2011.

[7] CNR DT200. Guide for the design and construction of an externally bonded FRP system for strengthening existing structures. Italian National Research Council, Rome, 2004.

[8] SF de Andrade, M Butler, S Hempel, RD Toledo Filho, and V Mechtcherine. Effects of elevated temperatures on the interface properties of carbon textile-reinforced concrete. Cement Concrete Comp, 48:26-34, 2014.

[9] J Donnini, F De Caso y Basalo, V Corinaldesi, G Lancioni, and A Nanni. Fabric-reinforced cementitious matrix behavior at high-temperature: Experimental and numerical results. Compos Part B-Eng, 108:108-121, 2017.

[10] SK Foster and LA Bisby. High temperature residual properties of externally bonded FRP systems. Proceedings of the 7th international symposium on fiber reinforced polymer reinforcement for reinforced concrete structures (FRPRCS-7), SP-230-70, pages 1235-1252, 2005. 
[11] AG Gibson, Y-S Wu, JT Evans, and AP Mouritz. Laminate theory analysis of composites under load in fire. J Compos Mater, 40(7):639-658, 2006.

[12] CA Harper and EM Petrie. Plastics materials and processes: a concise encyclopedia. John Wiley \& Sons, 2003.

[13] O Homoro, M Michel, and TN Baranger. Pull-out response of glass yarn from ettringite matrix: Effect of pre-impregnation and embedded length. Compos Sci Technol, 170:174-182, 2018.

[14] ICC-Evaluation Service. Acceptance criteria for masonry and concrete strengthening using fiber-reinforced cementitious matrix (FRCM) composite systems (AC434). Whittier, CA, 2013.

[15] M Jarrah, EP Najafabadi, MH Khaneghahi, and AV Oskouei. The effect of elevated temperatures on the tensile performance of GFRP and CFRP sheets. Constr Build Mater, 190:38-52, 2018.

[16] Y Li, X Liu, and M Wu. Mechanical properties of FRP-strengthened concrete at elevated temperature. Constr Build Mater, 134:424-432, 2017.

[17] CA Mahieux, KL Reifsnider, and SW Case. Property modeling across transition temperatures in PMC's: Part I. tensile properties. Appl Compos Mater, 8(4):217-234, 2001.

[18] SR Maroudas and CG Papanicolaou. Effect of high temperatures on the TRM-to-masonry bond. In Key Engineering Materials, volume 747, pages 533-541. Trans Tech Publ, 2017.

[19] M Messori, A Nobili, C Signorini, and A Sola. Mechanical performance of epoxy coated AR-glass fabric Textile Reinforced Mortar: Influence of coating thickness and formulation. Compos Part B-Eng, 149:135-143, 2018.

[20] A Nobili. Durability assessment of impregnated glass fabric reinforced cementitious matrix (GFRCM) composites in the alkaline and saline environments. Constr Build Mater, 105:465-471, 2016. 
[21] A Nobili and FO Falope. Impregnated carbon fabric-reinforced cementitious matrix composite for rehabilitation of the Finale Emilia hospital roofs: case study. J Compos Constr, 21(4):05017001, 2017.

[22] A Nobili and C Signorini. On the effect of curing time and environmental exposure on impregnated carbon fabric reinforced cementitious matrix (CFRCM) composite with design considerations. Compos Part B-Eng, 112: 300-313, 2017.

[23] L Ombres. Analysis of the bond between fabric reinforced cementitious mortar (FRCM) strengthening systems and concrete. Compos Part B-Eng, 69:418-426, 2015.

[24] L Ombres. Structural performances of thermally conditioned PBO FRCM confined concrete cylinders. Compos Struct, 176:1096-1106, 2017.

[25] DAS Rambo, F de Andrade Silva, RD Toledo Filho, and OFM Gomes. Effect of elevated temperatures on the mechanical behavior of basalt textile reinforced refractory concrete. Mater Design, 65:24-33, 2015.

[26] SM Raoof and DA Bournas. TRM versus FRP in flexural strengthening of RC beams: Behaviour at high temperatures. Constr Build Mater, 154: 424-437, 2017.

[27] RILEM Technical Committee 232-TDT. Test methods and design of textile reinforced concrete. Mater Struct, 49(12):4923-4927, 2016. ISSN 1871-6873.

[28] M Saafi. Effect of fire on FRP reinforced concrete members. Compos Struct, 58(1):11-20, 2002. doi: 10.1016/S0263-8223(02)00045-4.

[29] C Scheffler, SL Gao, R Plonka, E Mäder, S Hempel, M Butler, and V Mechtcherine. Interphase modification of alkali-resistant glass fibres and carbon fibres for Textile Reinforced Concrete II: Water adsorption and composite interphases. Compos Sci Technol, 69(7-8):905-912, 2009. 
[30] C Signorini, A Nobili, and FO Falope. Mechanical performance and crack pattern analysis of aged carbon fabric cementitious matrix (CFRCM) composites. Compos Struct, 202:1114 - 1120, 2018. Special issue dedicated to Ian Marshall.

[31] C Signorini, A Sola, A Nobili, and C Siligardi. Lime-cement Textile Reinforced Mortar (TRM) with modified interphase. J Appl Biomater Funct, 17(1):2280800019827823, 2019.

[32] Zoi C Tetta and Dionysios A Bournas. TRM vs FRP jacketing in shear strengthening of concrete members subjected to high temperatures. Compos Part B-Eng, 106:190-205, 2016.

[33] T Trapko. The effect of high temperature on the performance of CFRP and FRCM confined concrete elements. Compos Part B-Eng, 54:138-145, 2013.

[34] S Xu, L Shen, J Wang, and Y Fu. High temperature mechanical performance and micro interfacial adhesive failure of textile reinforced concrete thin-plate. J Zhejiang Univ-Sc A, 15(1):31-38, 2014. 